\title{
Turner's syndrome associated with bicuspid aortic stenosis and dissecting aortic $c$
} aneurysm

\author{
D. N. SLATER \\ B.Med.Sci., M.R.C.Path
}

\author{
M. J. GRUNDMAN \\ D.Phil., M.R.C.Path
}

\author{
L. MITCHELL \\ M.B., Ch.B.
}

The Department of Pathology, Royal Hallamshire Hospital, Sheffield and the Department of Medicine, Chesterfield $\overrightarrow{\vec{L}}$ Royal Hospital

\section{Summary}

A case of Turner's syndrome is described associated with bicuspid aortic stenosis and fatal rupture of a thoracic dissecting aortic aneurysm. Histology of the aneurysm showed severe cystic medial necrosis. This association has not been previously described in the absence of coarctation.

In view of the possibility of surgical repair, dissecting aortic aneurysm should be considered in all patients with Turner's syndrome presenting with chest pain, irrespective of the presence or absence of coarctation.

\section{Introduction}

Cardiovascular abnormalities occur in $35-50 \%$ of patients with Turner's syndrome (Braunwald, 1980). Coarctation accounts for $70 \%$ of these abnormalities and others include a bicuspid aortic valve, idiopathic hypertrophic subaortic stenosis, ventricular septal defect, mitral valve prolapse and dextrocardia (Braunwald, 1980).

\section{Case report}

A 40-year-old female presented in November 1980 with a sudden onset of upper central chest pain radiating to the jaw. This lasted for 10 minutes and was followed by sweating, syncope and urinary incontinence. The pain persisted for another ten minutes in the interscapular area.

She had been seen previously by a gynaecologist in 1957 for primary amenorrhoea. Examination at that time revealed a female of short stature with poorly developed secondary sexual characteristics and a bilaterally webbed neck. Examination under general anaesthesia showed the presence of an infantile uterus and the clinical diagnosis of Turner's syn- drome was further supported by a buccal smear. examination. Formal chromosome studies were not $\vec{\omega}$ performed. An apical midsystolic murmur (grade II) was also noted and in 1958 the webs were surgically? excised.

Examination on admission to hospital in $1980 \subseteq$ showed a woman of short stature (4ft 11 in) with low set ears and bilateral linear surgical scars on the neck. $\mathscr{\bullet}_{0}$ The breasts were poorly developed and the areolge ${ }^{\circ}$ were absent.

The pulse was 80 per min, regular, with a pogrs volume and slow rise: the blood pressure was $100 / 70 \mathrm{D}$ $\mathrm{mmHg}$, the apex beat was thrusting in nature ando displaced to the anterior axillary line in the 6th $\frac{}{\odot}$ intercostal space.

There was a systolic thrill in the aortic area and $\overline{\overline{0}}$ right side of the neck and a grade VI systolic murmur was heard in the aortic area. The femoral and radialo pulses were present and not delayed.

The electrocardiogram showed sinus rhythm with normal voltage $Q R S$ complexes and an axis of plus: $45^{\circ}$. It was regarded as within normal limits.

A clinical diagnosis was made of aortic stenosis with angina and the patient was rested in bed. Arrangements for further cardiological investigations 0 were made but before they could be implemented she $?$ suddenly collapsed $48 \mathrm{hr}$ after admission.

\section{Post-mortem}

Examination revealed that the cause of death was $\mathrm{a}^{\mathrm{\omega}}$ haemopericardium $(700 \mathrm{ml})$ that had originated from? a ruptured dissecting aneurysm of the ascending thoracic aorta (Fig. 1). Histological study of the aneurysm showed the widespread accumulation of ${ }^{+}$ acid mucopolysaccharide in the aortic media with ${ }_{\bar{C}}^{0}$ fragmentation of the elastic fibres (Fig. 2). The aorta若 


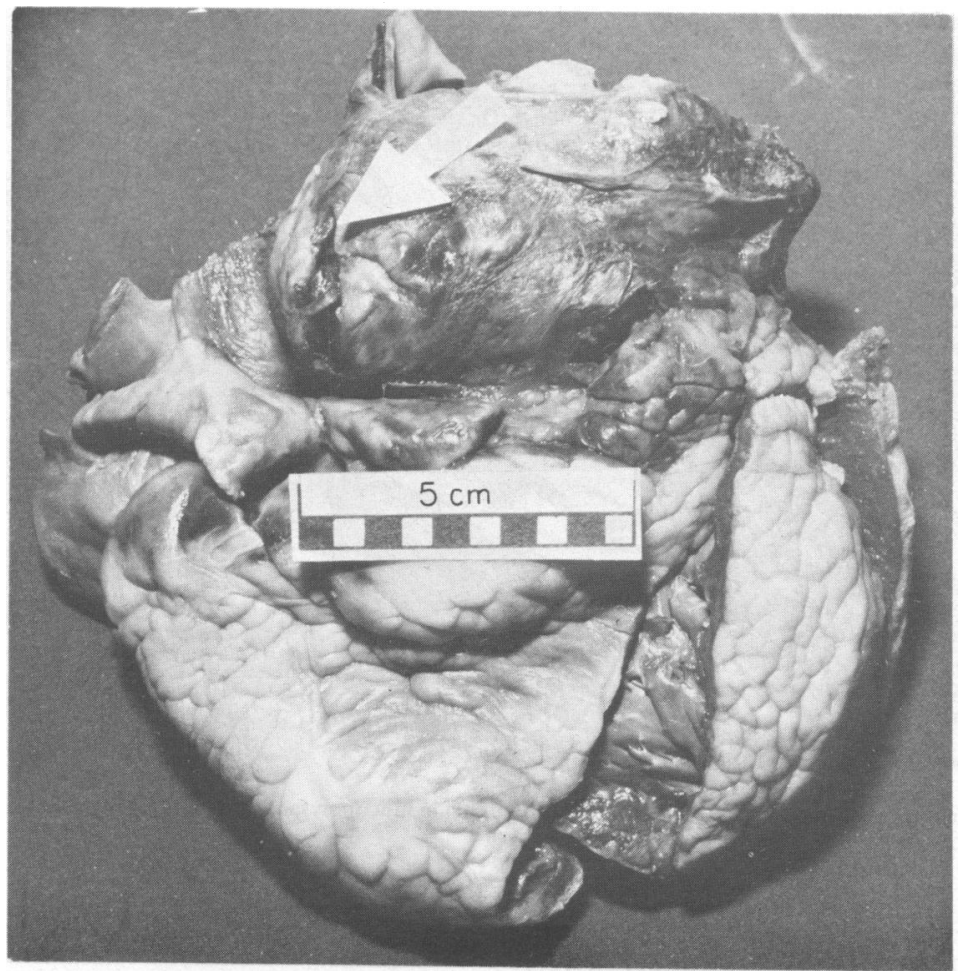

FIG. 1. Site of rupture (arrow) of dissecting aneurysm in the ascending aorta.

showed no evidence of coarctation and was histologically normal in areas distant from the aneurysm.

The aortic valve was bicuspid and stenotic. There was valve fibrosis but no calcification. The left ventricle was hypertrophied and histologically showed no evidence of ischaemic changes.

\section{Discussion}

Dissecting aortic aneurysm has occasionally been reported in Turner's syndrome. However, in all previous cases the aneurysm appears to have been associated with coarctation. Anabtawi et al. (1964) described a 31-year-old hypertensive patient with Turner's syndrome who died following the surgical repair of an aneurysm situated distal to a coarctation. A calcified bicuspid aortic valve was also present. Selgado (1961) reported a case of Turner's syndrome associated with a dissecting aneurysm and although the term coarctation was not used in the paper, an area of aortic narrowing proximal to the aneurysm was described.

The reason why a dissecting aneurysm developed in our patient remains uncertain. However, McKusick, Logue and Bahnson (1951) reported four cases of aortic valvular disease associated with cystic medial necrosis of the ascending aorta and suggested that the association represented a new syndrome. This view was later supported by Fakunda, Tadavarthy and Edward (1976) who described an additional six cases. In each instance stenosis was the predominant lesion and the authors suggested that the medial necrosis was secondary to unusual local haemodynamic stresses. A similar situation has been observed in the development of dissecting aneurysms distal to supravalvular stenosis (Marrow et al., 1959) and coarctation (McCombs and Crocker, 1967).

The degree of cystic medial necrosis in this case was considered to be grade IV according to classifications by both Pomerance, Yacoub and Gula (1977) and Carlson, Lillehei and Edward (1970). This is in excess of medial changes associated with ageing and has been observed in post-stenotic dilatation (Pomerance et al., 1977).

A direct association between Turner's syndrome and vascular abnormalities has also been suggested. Doerr and Koch (1958) described abnormalities of the elastic tissue in the pulmonary veins of cases of Turner's syndrome. The appearance was similar to aortic cystic medial necrosis. However, histological studies of the pulmonary veins in our case were 


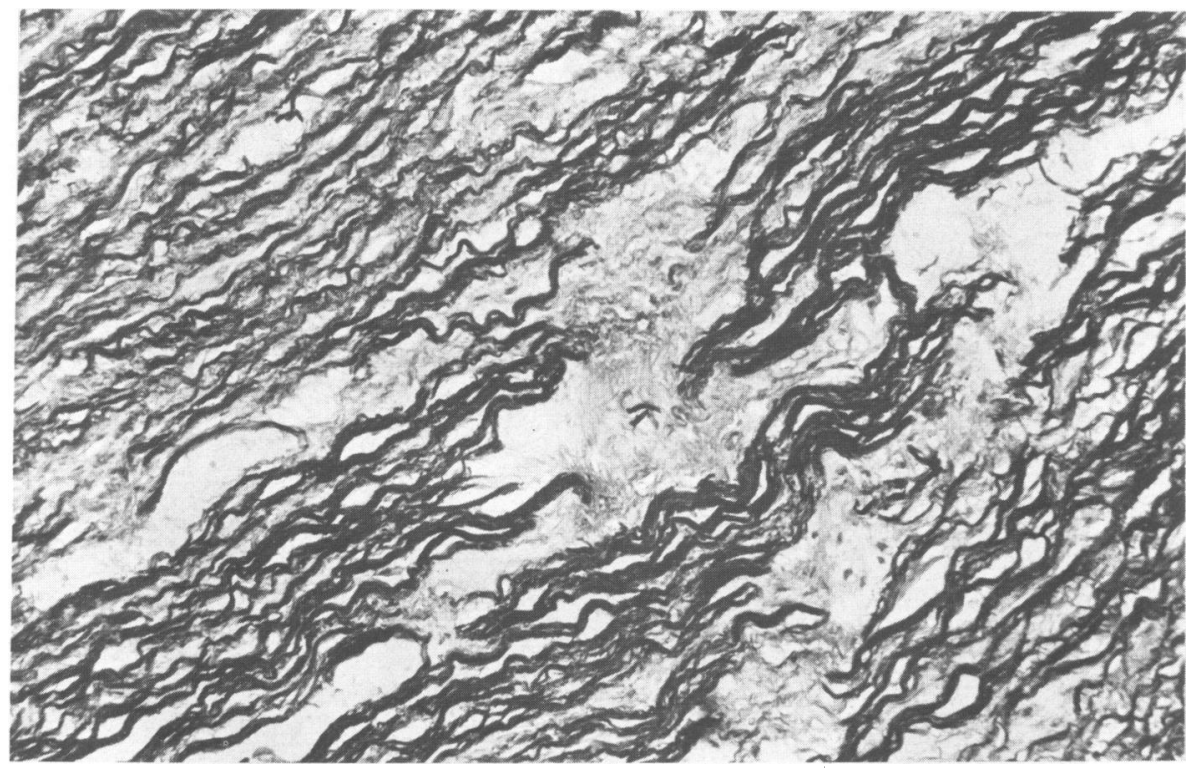

FIG. 2. Widespread fragmentation of elastic fibres and accumulation of acide mucopolysaccharde in the aorta adjacent to the rupture (Alcian $\vec{c}$ blue-elastic-van Giesson, X 240).

normal. A possible relationship between oestrogen and progesterone balance has also been suggested by Mandel, Evans and Walford (1954) and this is of interest in view of the endocrine disturbance in Turner's syndrome.

In view of the possibility of surgical repair, dissecting aortic aneurysm should be considered in all patients with Turner's syndrome presenting with chest pain, irrespective of the presence or absence of coarctation.

\section{References}

ANabtawi, I.N., Ellison, R.G., Yeh, T.J. \& Hall, D.P. (1964) Dissecting aneurysm of aorta associated with Turner's syndrome. Journal of Thoracic Surgery, 47, 750.

BRAUNW ALD, E. (1980) Heart disease, $A$ Textbook of Cardiovascular Medicine Vol 2, p. 1692. W. B. Saunders \& Company, Philadelphia.

CARlson, R.G., LILlehel, C.W. \& EDWARD, J.E. (1970) Cystic medical necrosis of the ascending aorta in relation to age and hypertension. American Journal of Cardiology, 25, 411.
DOERR, W. \& KOCH, H. (1958) Uber eine texturstorung de्g Lungenvenenwande in einem Falle von sogenanntem Turnes Syndrom. Archiv für Kreislaufforschung, 29, 1.

FAKUNDA, T., TADVARTHY, S.M. \& EDWARD, J.E. (1976) Dissectin aneurysm of aortia complicated by valular stenosis. Circulation, 53, 169.

MANDEL, W., Evans, E.W. \& WALFoRd, R.L. (1954) Dissecting 弚 aortic aneurysm during pregnancy. New England Journal of $₫$ Medicine, 251, 1059.

Marrow, A.G., Waldhausen, J.A., Peters, R.L., Bloodwell, R.D. \& BRAUNWALD, E. (1959) Supravalvular stenosis. Clinical haemodynamic and pathologic observations. Circulation, 20, 1003.

MCCOMBS, H.L. \& CROCKER, D.W. (1967) Dissecting aneurysm distal to coarctation of the aorta with long survival. American Heart Journal, 74, 675.

McKusick, V.A., Logue, R.B. \& Bahnson, H.T. (1951) Association of aortic valvular disease and cystic medial necrosis of the ascending aorta. Report of four instances. Circulation, 16, 188.

Pomerance, A., YACoUb, M.G. \& GUlA, G. (1977) The surgical pathology of thoracic aortic aneurysms. Histopathology, 1, 257.

SElgado, C.R. (1961). Turner's syndrome. Report of a case associated with dissecting aneurysm of the aorta. Revista de la $\mathrm{S}$ Facultad de ciencias médicas de la Universidad nacional de Córdoba, 19, 193. 